\title{
Urban Population Behaviour and Knowledge Assessment about Water Quality, Consumption, and Conservation in Pakistan
}

\author{
Mohammad Qasim ${ }^{1}$, Shabbir Ahmad ${ }^{2, *}$, Saira Akhtar ${ }^{3}$, Shakeel Imran $^{1}$, Kashif Nazir Qureshi ${ }^{1}$ \\ ${ }^{1}$ University of Agriculture, Faisalabad, Sub Campus, Burewala-Vehari, Pakistan \\ ${ }^{2}$ College of Humanities and Development Studies, China Agricultural University, China \\ ${ }^{3}$ Department of Rural Sociology, University of Agriculture, Faisalabad, Pakistan
}

Copyright $\mathrm{C} 2018$ by authors, all rights reserved. Authors agree that this article remains permanently open access under the terms of the Creative Commons Attribution License 4.0 International License

\begin{abstract}
The scarcity of potable and drinking water has created great economic constraint upon the urban public in South Asia. The demand has increased ten folds while the supply although being abundant in ground and surface water rich areas has dwindled. Sustainable approaches to managing water require integrated management while community engagement lacks due to the technology unawareness and being deficient of water policies. Community acceptance regarding water policies is based on the knowledge which is a by-product of information and active engagement. While identifying community engagement, we verified local population knowledge-base and awareness about sustainable and integrated water management. To gain full knowledge we developed a case study to learn it from the community across Pakistan. The research instrument was designed to measure knowledge about water and the related factor contributing to conservation. The study was based on interviews of twenty-five thousand households selected through stratified sampling method in five large cities of the Punjab namely, Lahore, Multan, Rawalpindi, Gujranwala, and Faisalabad. We selected five thousand households in each of the urban areas. The study also measured psychological, health, environment, and water related activities. We also measured the impact of the monsoon season which impacts and recharges the ground water during the summer months. The responses were explanatory directing our attention towards strict water policy, urban water cycle issues, lack of proper solid waste disposal and absence of sewage treatment facilities. However, our finding of water knowledge was directly connected with the seniority in age, coupled with higher education and knowledge of health and water borne diseases. While the deficiency of knowledge and related actions towards policy formation were the direct result of not knowing modern languages of education, poverty, lack of access to information and gender biases. Lower water
\end{abstract}

knowledge was a by-product of non-comprehension of the water filtration techniques, water harvesting of rainwater and knowledge of water scarcity and the procedures of protecting ground and surface water from the pollution of several types.

Keywords Water Knowledge, Pakistan Water Management, Urban Water Use, Water Pollution, Sanitary Conditions

\section{Introduction}

Dwindling water resources require the adaptation of sustainable water management policies and teaching the public of integrated water management techniques. Since water in urban areas with the abundance of fresh water resources is forecasting huge water deficit soon, therefore imminent actions are needed. While water quality and quantity are degrading, and water tables are being lowered but there seems to be no mindfulness for the public as well as the government officials and policy makers in developing countries and in the case of this research in South Asia and particularly in Pakistan [1]. There are severe warnings being issued by environmentalists regarding the coming age of fresh water scarcity but due to the non-existence of water education as well as absence of sound water policies these warnings are not being heeded and as a result the future of the Punjab (land of five waters) is under a great threat [2]. Climate change is another factor, which requires attention because severe droughts in some areas of the Punjab also depict that the challenge is real and if policies, as well as actions at gross-root levels, are not taken then the consequence of water scarcity will engulf the whole of the Punjab in the coming years [3].

The imminent challenge to quick depletion of the fresh 
water is domestic and commercial pumping the excessive and abusive large-scale private pumping. Most of the pumped water runs off into drains with no constraints because of the illiteracy in water knowledge about scarcity being a precious commodity. The situation is grave in urban areas where runoff is so huge that the sewage lines laid for the sewage and waste water are overflowing with runaway pumped water freely being discharged into the drainage systems. Then the water cycle knowledge in urban and rural population alike has also significant impact because no one knows how the water cycles naturally operate and what actions are required to make the return of more rains and then management of the rainwater by harvesting and storing. There are several approaches which are variously referred to as 'integrated water management', 'sustainable water management', 'water sensitive policies', with the addition of 'total water cycle management' [4].

Therefore, the introduction of water pumping and use control and management programs are necessary because they not only reduce the water in water ways but also help reduce pollution and develop a continuous water management campaign which allows populations to join hands and develop water knowledge for greater positive benefits. The citizen engagement is the first step in recognizing that there is a water issue requiring correction and overview. Then developing water management boards with active steering committees in each commune, cognitive knowledge awareness about water, adoption of water curriculum in schools and colleges, development of water policy a priority, and production of water aware specialists and experts in communities are thus the hallmark of the integrated water management protocols. The engaged citizens are those who comprehend the value of water, its sustainable use and are continuously engaged in the development and adoption of contemporary water technologies [5]. These citizens are also part of the political putsch of water policies and data management to lobby law-makers in the greater development of water infrastructure. The need also increases as there is the requirement of un commercialization of the water industry and development of more support for community-based water management. Since community-based actions can have the significant impact on commercial water demand, therefore, community opposition to the commercialization of water sheds and put the community at the mercy of water merchants can be deviated with communal water schemes and with the demonstration of community support initiatives. Most of the research review provides insights towards the importance of pro environmental attitudes and communal behaviors for beneficial water uses. Then there are very few investigations available which produce deep insights on communal and citizenry practices and attitude insights regarding water uses. It is sad to state that majority of the citizenry takes water as granted with no remorse on waste and pollution [6]. Therefore, the research is first of its kind developing a relationship. The aim of the study is transparent which is (a) to assess and quantify water based communal knowledge, (b) examination and cataloguing of social and cultural factors associated with water, (c) exploration of relationship between knowledge and water policy, (d) and development of a chart of integrated water management with applicable tools and nodes.

\section{The Importance of Awareness}

Community awareness and possession of knowledge is the main key factor of solving water problems. The knowledge is also the key element of generating engagement because the knowledge generates communal responses towards solutions, innovation, adoption of newer technologies, and the support for greater water policies. The term 'water literacy', 'health literacy', 'environmental health' 'water capacity building' and development of water acquaintance to affect the water policies are the very actions needed for sustainable water management.

\section{Past Research and Community Knowledge}

Water awareness has gained momentum in recent years. However, the history of first water bottled being sold in the United States is traced to the 19th century which is that in 1845 the Ricker family of Maine first bottled and sold water then it was Poland Springs and then the Ozarka Water bottle company was founded in 1905 in Eureka, Arkansas. The main reason of bottled water is the pollution and impurity of potable water due to various and diversified reasons. However, between these times, there was very little activity in the bottled water industry which suddenly rose to its peaks as purified water became popular as Coca Cola and other soft drink retailer started the pure water campaigns against declining sales of sugary water labeled as cola and soft drinks [7]. There is an exception to mineral water which has been a product of attraction for people due to its mineral and special healthy contents. The bottled water available in the market is just a product with healthy and pure contents with the intent to protect human health, safety and diseases. In developing countries, the water market has grown larger due to the absence of sanitation, water scarcity, and availability factors. In some arid areas of South Asia, water production has been mainly connected to the female and young girls. In classic films and movies, girls are depicted fetching water from the common communal well in the village or have been shown fetching water from the nearby river or the local stream. The reasons of the classical water transport have been unavailability and not the health and pollution [8]. Global water collection was due to the scarcity but in the U.S. the water bottling took place due to the commercialization factors. The U.S. has a lobbying industry and culturally when there is an issue of development of any industry the lobbying must take place to regulate through legislation [9]. The lobbying provides controls to the industry and at the 
same time, it develops minimum standards and basic thresholds for the given protocol [10]. Many groups involved in the lobbying for water commercialization since 1950 have emerged recently successful for the promotion of their commercial water products. These groups can be listed as mega corporations spread across many nations.

Mineral water is considered a rare commodity are sold based on the content while bottled water has a different premise, unlike the tea, coffee, and the soda. The bottling of water is purely western, but it has been adopted globally due to the premise that it is only water that is pure and has no other contents. Branding of water is another element which has promoted bottled water at a rapid rate [11]. Since many multinational companies are involved in promoting soft drinks, they have also engaged in the water industry as well. Their take on the bottled water is the same because huge pollution in the atmosphere and on the land in many of the developing countries has placed the normal individual to the margin as the health is concerned. Due to the higher rate of pollution and impurity of the available water in the world has sparked the demand for higher rates [12]. One interesting fact is that in the U.S. alone there are more than seventy-five water brands.

In Pakistan, there have been several "water based" researches where the important thing is that it is not the water scarcity increasing the water research and the knowledge rather it is the expansion of the higher education institutions due to expansion in the higher education initiatives since the 1990s. The main evidence is that prior to the 1990s there were only seven universities in Pakistan but in 2017 one can witness of 183 universities registered with the higher education commission of the nation. Therefore, the horizontal expansion in water knowledge is due to the water-based degrees being offered in the nation which stands at 45 now [13].

However, when surveying the local knowledge about water sources majority of the respondents answered that main source of drinking water was to be the ground water while only a mere small segment of $13 \%$ related the water source to be the surface water whether it was a stream, river, rain or the spring. $63 \%$ of those surveyed were unaware of the terms such as watershed (catchment), estuary, and the integrated water management techniques. $83 \%$ of the surveyed population described that earth was filled with water just below the ground at about 100 feet below. It was another fascinating fact to learn that almost $98 \%$ responded that they never received any water related education at the school, college and or the university and the exception were of those who have studied abroad. A large segment of the population did not know anything about the water shortages caused by nature. Rather the water shortage described was due to the municipal rationing. The knowledge of water shortage was belonging to the populations in the desert and semi desert and mountain areas. Another interesting element was discovered when the question of the storm water and the sewage was posed.
The response was shockingly surprising those $85 \%$ respondents if they have no knowledge that these surplus waters were being released into the freshwater streams such as river and ravine. The domestic waste water treatment was learned that $91 \%$ did not know that refuse water could be treated and cleaned before entering the waterways.

Many disciplines are established but the water literacy has not been developed to include specific areas of knowledge. The emerging emphasis on integrated management and sustainable water use suggests that individual knowledge-based expansion is necessary, and the urban water cycle knowledge is needed to be embedded into the individual knowledgebase. The impact of urbanization, water pollution, scarcity, ground water depletion, storm water and sewage mixing, waterways and floodplain encroachment, water treatment, microbial life and water quality are the several important domain needs including in the far lagging behind water education in the nation. The necessary support lacking the water research need to be developed in institutions, municipal boards, and integrated water management techniques first need to be developed in water curriculum across the nation and then systematically to be included into the municipal water management practices.

Cataloging water knowledge of individuals is important for a variety of factors. The main benefit which can be drawn out of this research is that when considering initiation and development of water policy, the existing community knowledge can play a pivotal role in the development of policy goals and actions. Identification of weakness and awareness of strengths do provide an important foundation when the policy actions are developed not to be the output rather to be the outcome based.

An alarming $80 \%$ of the untreated sewage flows into the river and water bodies of India without any restriction. The same water bodies flow into the Pakistan and mainly Punjab and Sindh provinces where both are densely populated and there is no treaty or the international accord, which could measure, test, verify and remedy the cross-border water pollution. Pakistan also releases its huge quantity of wastewater into the water bodies flowing across the nation. Public awareness in both nations has reached a record level low because an enormous number of the public bathes, washes, drinks and utilizes the untreated sewage infested water for personal use as well as for crop irrigation. Heavy metals, industrial effluents, hospital waste, chemical and pesticide laden refuse alongside the silt, and land sliding materials can be seen in all water bodies flowing internally or coming in from the Northern borders of Pakistan. Here the government official's awareness is also very low because there are no departments and no specialists available, which could verify the water pollution and its increasing level of population health threatening effects. 


\section{Remedies of Water Pollution}

Water pollution remedies also vary in south Asia. The first remedy available is to take the guilty party to the court through legal action. In Pakistan and India, both the British law of the nineteenth century is practiced. It is defined as a public nuisance to pollute a water body by means of making it unusable, hazardous to public health, aesthetics and other characters, which are the natural part of the water body. A legal action with private remedies can also be sought in the court. In addition, the Indian Penal Code also provides penalties under section 29 and 268 of 1860 . There is also criminal proceeding defined in sections 133 to 144 providing the authority to the magistrate to introduce the remedy within a fixed period. Another interesting element is the legal action through the public interest is only through the litigation. Which means that a legal action in the High court, or in the Supreme Court can be initiated under the greater public welfare philosophy protected by the Articles 32 and 226 of the Indian Constitution for the enforcement of an action to protect the public interest and the natural resource.

In Pakistan, similarly, the Penal code of 1860 adopted by the nation provides same remedies offered and described under the Indian court system. However, it does not go beyond the declaration of nuisance and requesting the court to issue an injunction to stop and control it. The statues do not look beyond the issue of simple fines and payment of damages to the affected parties. The issue of clean water in South Asia is grossly underestimated but there are no concrete actions or legislation being carried out to tame the menace. One of the early studies in Pakistan provided that the urban dwellers were aware of the water scarcity who faced the dilemma due to unavailability of the municipal water or the water was not available from the underground water table pumped by the individual hand pump. Communities were unaware of the water saving techniques and they could not offer any solutions to reduce water scarcity except offering a storage tank inside their homes. In our study, only $32 \%$ could identify that water underground existed in water table form and not in a water layer under the hard layer of earth.

Water related knowledge was worst among the urban dwellers who were completely ignorant of the municipal waste water effects. There were $83 \%$ of those surveyed declared that sewage water automatically got treated by nature by penetrating the ground leaving the pollution and chemical on the surface and similarly $72 \%$ exclaimed that water when evaporated into the air did not leave any harmful and hazardous residues on the ground. Another $67 \%$ claimed that the hazards and pollutants dried out of the evaporated sewage could not cause any harm to the communal health because they got scattered into the air and were "blown away". The away concept about pollution and waste was so predominantly prevailing that $91 \%$ claimed that air was a natural and God created the element, which could purify their pollution from the water and from the ground.

When questions were posed of the storm water and the waterway, a huge $93 \%$ could not identify that unrestricted land use could cause flooding and the waterborne diseases could be borne out of the unrestricted water flow. Mixing of the storm water and the waste water questions also received similar responses that $81 \%$ could not define the difference between the waste and the storm water. Rain water as it was identified and mixing it with the waste water was a widespread practice to $84 \%$ of those surveyed and if it could not cause any harm because the storm water caused dilution to the waste water and then it carried away faster from the human habitat.

When seeking information about the wastewater treatment facilities, $98 \%$ if they have no knowledge whether there were any waste water treatment plants installed into any of the Pakistani cities. Similarly, the local government and municipal, officials were ignorant of the treatment and could not identify whether there was any waste water treatment facility in their vicinity. When the question of the source of the drinking water was raised, $88 \%$ responded and pointed it to the ground water while $11 \%$ described it from the local water stream or the oasis. These respondents were further discovered to be from the mountain regions where there was no possibility of the ground water pumping facilities and possibilities.

\section{Foundation of Water Knowledge}

Thales's Spherical Earth is the basic water theory, which was based on the idea that earth floats on water. Aristotle, however, revised the theory, with the knowledge, which evolved with the passage of the time and has become the foundation of our current water knowledge. However, it was surprising to learn that $29 \%$ of those surveyed still assumed that the water below the surface was equally distributed and the same water quality and the quantity was available across Pakistan. The only difference was that in mountains, water could not be reached due to the hard-rocky surface and similarly, it could be equally reached in desert and sandy areas. Similarly, there are two other types of theories, which form the foundation of our water knowledge, the first one is identified as Cattel's Investment theory.

These theories are derived from the human intelligence development stages. The two stages of human knowledge development are fluid intelligence which lasts way into the adulthood and then the concrete intelligence which once developed lasts for a lifetime. The first explains that human knowledge passes through developmental stages where knowledge received by the brain is constantly updated and remains fluid until hard and concrete evidence provides that the results being observed in each scenario are final and repetitive. At this stage, the human brain enters the second stage of the 'crystallized intelligence' which simply means that the knowledge has formed into a solid state and change in developed ideologies are rarely to take place. An 
adult human does have crystallized intelligence where the knowledge may be faulty or fictitious, but the individual holds the information sacred and applies it to instances where decisions are needed. Similarly, the water knowledge received by individuals in a society should be from reliable and scientific sources but due to the absence of the same, the knowledge crystallized into the populations is based on the street and chance instances which in return creates biased and false perceptions and associated with unsustainable and unhealthy water usage practices.

Other determinants of water knowledge are based on two dimensions described and researched by Kohn and Simon (1968). Their research determined that there are types of knowledge, which are local, and then there are those, which are trans-territorial. Local knowledge then is based on situational and then situational specific. For example, the theory of fright, fight, flight is based on three valid observations of species where in times of danger and conflict these three behavior characteristics are observed in species. Similarly, these are based on instincts because the science has not been advanced to the degrees that it may explore the behavior and knowledge and behavior patterns of many planetary lives. Similarly, trans-situational factors are spread across large domains. These are learned through systemized educational process while the situation specific knowledge is based upon subjective experiences, which may be regional, cultural and or perceptive.

\section{Water Borne Diseases Origins Exposed}

Increased campaign about water safety, pollution and of water borne diseases has been a major factor informing and educating the public about water knowledge. However, the specificity of the knowledge is where the main research of this paper is being carried out. When discussed on streets, the water taste, color, and turbidity are visible and simple signs of water safety and purity. The main issue regarding the water knowledge is not about the common characteristics but of microbial life, hazardous chemical and their contamination into the drinking water sources as well as into the ground water. It is imperative that water is the lifeline of the planetary life and its contamination and or decline will cause the life to vanish from the earth. The considerable number of populations are sick, and their diseases are borne out of the water related issues but there is no preventive treatment in hospitals, government information bureaus, media campaigns and or the community outreaches. The only time there is information dissemination about the water health risk when there is a major outbreak of diseases returning into a disaster else all is okay and the water fulfilling the taste, color, and turbidity test is considered safe for human and animal consumption. According to the World Health Organization, an alarming $80 \%$ of the population across developing nations is suffering from water-borne diseases. The impact of ignorance of water knowledge is so great that in the South Asian markets and bazaars, the sugar cane fresh juice drink, sweet and sour drink (Imli-Aloo Bukhara Drink), crushed ice treats, roasted barley grain drinks are also very common and quite popular in Pakistan alongside the fresh squeezed lemonade and sweet curd drinks. These drinks are widely available on pushcarts and a considerable proportion of populations consume it without any regard to health hazards or the suspicion of water borne diseases, pollution and or infectious contamination. The vendor utilizes glass cups, which are then washed within the water bucket just to eliminate the residues of the previous customer from the drinking cup. The water stored in the plastic bucket is continuously utilized until it becomes turbid and smelly. The mixing of various contaminants, germs, bacteria, dust and chemical particles being blown streets and bazaars become part of the street summer drink and many populations do contract diseases from this unhealthy, un-sanitized and unregulated industry of summer drinks.

Another element of lack of water knowledge is huge unemployment in South Asia and especially in Pakistani cities. People lacking skills are thronging into cities in search of a better lifestyle and improved economics. Faced with uncertain future and unemployment, many of these individuals take up the self-employment into selling items of fast consumption on streets and alongside roads and bazaars. Many individuals can be spotted in streets offering several types of products and food items for fast consumption. These individuals often purchase their materials from vendors not certified and without any origin. These vendors in the quest for high profits do peddle products, which are not standardized, are fake, expired and or are prepared in unregulated manners. Locally produced milk drinks are often the product of unhealthy and low-quality milk powder while soft drinks are produced with the use of tap water and under unhygienic conditions. A clear majority of these soft drink factories are home driven and are in densely populated quarters with unskilled, illiterate and are produced with the mixture of a large variety of unhealthy ingredients. These unregulated and uncontrolled summer drink peddlers are also involved in filling used water bottles with tap water and then marketing it to unsuspected customers at bus stops and on remote locations [14].

\section{Impact of Water Knowledge Upon Water Consumption Behaviour}

Human behavior about the environment is heavily dependent upon factors involved in the nurturing of the individual. In agrarian societies, water is considered a sacred commodity and any damage to water bodies and or towards pollution is considered a violation of the celestial and cultural code [15]. In urban societies where populations are fluid, the presence of a large segment of the 
uneducated and illiterate population poses certain degrees of dangers to overall population behavior. The absence of environmental education and knowledge of 'water cycle' can be the determinant of the water consumption and water treatment behavior. Similarly, sufficient knowledge is also the core of the behavior change patterns. Social, cultural, moral, psychological, and economics are also vital in the formation of water knowledge in an individual's mind frame. The pricing of water is also a factor, which determines the mindset regarding the water policies and their support. Water knowledge and support are extended when individuals are not directly related to the impact rather it is an extension where for the group welfare such policies are being offered. There is a relationship, which indicates a direct link between water knowledge and support for the water policies with the absence of direct benefits [16]. This study has extended the research on defining the relationship of general water knowledge and the support for water purity, human health and environmental health and safety.

There is a gap between the broad water-based knowledge and the communal behavior among South Asian populations which identifies breaches resulting in the development of health hazardous environment and lassie faire approaches towards water treatment and purification.

Southern Punjab in South Asia is the rich environment, which provides ample opportunities for water research into gauging the water knowledge in the urban and rural adult and then verifying it with the communal health and environmental data across the nation. Moving beyond the drinking water consumption levels, the research also identified the behavior and knowledge of the population across into larger water issues such as drought, water bodies. The research also posed questions about the drought, larger water bodies management, water storage, integrated water management, flooding, and management of water bodies with sustainable methods and procedures. The study addressed the questions of (i) various water issues in the environment, (ii) water issues among populations, (iii) water safety and security, (iv) water management, (v) integrated water management, (v) water behavior historically held by an individual and or the society, (vi) altered water behavior after education and awareness campaign, (vii) waste water treatment, (viii) natural water bodies protection, (ix) and support for water policies. Additionally, this research provides insights towards the issues listed here and then moves into providing the useful solutions and actionable suggestions assuring that water knowledge is increased, and safe water practice are adopted. Further, actionable agendas can be formed when this research is put into practice and a range of initiatives can be adopted from individuals to communal levels and forging water safety campaigns with participatory initiatives.

\section{Materials and Methods}

\section{Study Design}

There were 25,000 households spread out in five large cities of the Punjab were selected through questionnaire surveys, interviews, observations, and review of historic data to explore the water knowledge in the Pakistani community. These households were selected randomly and were accompanied by the Census March- April 2017 teams, therefore, the validity and reliability of the data was not marginalized. All surveys were administered individually and personally and there was no data received from the online or internet surveys. The study was privately funded by the local NGO and a team of five researchers was involved in preparing and administering the study and the investigations.

Assessment of the data were carried out in the statistical package where thirty-three items listed below were verified with several questions into each category, therefore, making the study comprehensive and detailed. These items were based on the study objectives and were developed by the study team.

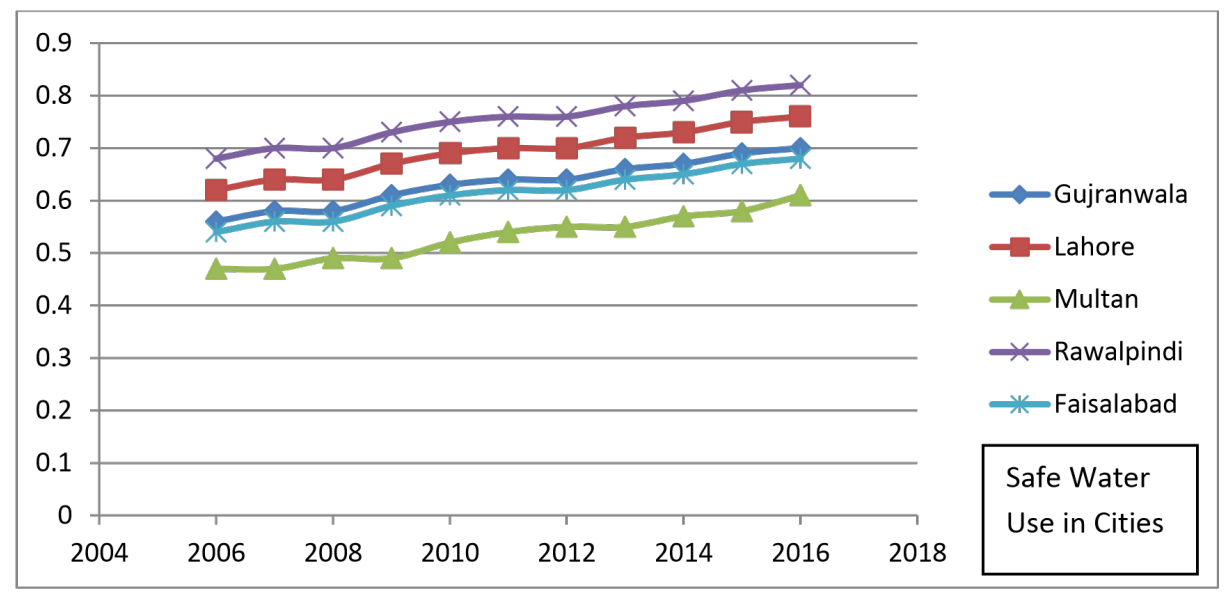

Figure 1. Normal distribution of extended dataset 


\section{Results and Discussion}

Thirty-three items were rated on a5-point Likert scale ( $1=$ 'strongly disagree' to $5=$ 'strongly agree'). A 'don't know' option was also included. A Likert-type scale was used in preference to true/false responses, as true/false items can produce elevated levels of missing data when used to measure objective knowledge of environmental issues. Eight items were framed such that the correct response was 'agree'/ 'strongly agree'; six items were worded such that the correct response was 'disagree'/ 'strongly disagree'. Neutral responses ('don't know' or 'neither disagree or agree') were coded as incorrect. Finally, one item used a multiple-choice response ('which of the following options best represents your understanding of what a catchment is?' Responses options were: (a) The are at hat retains water like a wet land or a marsh; (b) All the land area that drains to a specific river or waterway (correct).

Table 1. General data responses and Weighted Data responses

\begin{tabular}{|c|c|c|}
\hline \multicolumn{3}{|c|}{ Responses to water knowledge information (house hold waited data) } \\
\hline Sr. \# & Information Query & $\%$ corrected $(\mathrm{n}) \mathrm{weighted}$ data \\
\hline 1 & Water ways can be damages by rain water and floods & $.7495(18773)$ \\
\hline 2 & $\begin{array}{l}\text { Waste water form bathrooms and latrines receives no treatment before entering the } \\
\text { water ways }\end{array}$ & .9789 (24472) \\
\hline 3 & $\begin{array}{l}\text { Water conservations actions can significantly reduce the amount of water used in } \\
\text { urban areas }\end{array}$ & $.8486(21215)$ \\
\hline 4 & Domestic water and rain / storm water are carried through the same pipes & $.9432(23580)$ \\
\hline 5 & Water source for house hold uses is ground water & $.8437(21092)$ \\
\hline 6 & Water quantity daily in use is acceptable for human consumption & $0.3267(8167)$ \\
\hline 7 & There are many types of water pollution types as per my knowledge & $.7922(19805)$ \\
\hline 8 & I don't know of any water safety tips or procedures taught to me are learned directly & $.6632(16580)$ \\
\hline 9 & How do you handle water (open or use containers) in daily uses? & $.5634(14085)$ \\
\hline 10 & $\begin{array}{l}\text { I use same water for drinking and washing and bathing purposes stored in a single } \\
\text { tank }\end{array}$ & $.7276(18190)$ \\
\hline 11 & All water consumers add some types of pollution into the waste water? & $.9433(23582)$ \\
\hline 12 & Water quality and safety in good from water wells, hand pumps and turbines? & $.7982(19955)$ \\
\hline 13 & $\begin{array}{l}\text { I have never faced any water shortage except the municipality water breakdown in my } \\
\text { life time? }\end{array}$ & $.9568(23920)$ \\
\hline 14 & Have you or any one you know has had done the rain water harvesting? & $.08144(20360)$ \\
\hline 15 & I always use water purification filters for drinking and house hold water? & $.3853(9632)$ \\
\hline 16 & I do verify the land soil and type of moisture for gardens and crops for water irrigation & $.5634(14085)$ \\
\hline 17 & I have read at least one book on water and its cycle and on management & $.0763(1907)$ \\
\hline 18 & I Know of at least one government regulation about water & $.0474(1185)$ \\
\hline 19 & Wife, husband, family has good knowledge of water issues & $.0253(632)$ \\
\hline 20 & Wasting water is a moral and social crime & $.6489(16222)$ \\
\hline 21 & Worried of water crises local or global in your life time & $.8894(22235)$ \\
\hline 22 & I often experience open and bubbling gutters in my neighborhood & $.7974(19935)$ \\
\hline 23 & I know someone who got sick of contaminated water & $.9251(23127)$ \\
\hline 24 & I think u se of waste water for crops and vegetables causes disease and cancers & $.8984(22460)$ \\
\hline 25 & If you know these are waste water crops, would you still consider buying them & $.0395(987)$ \\
\hline 26 & Soaps and detergents pose dangerous chemical to water bodies and water tables & $.9872(24680)$ \\
\hline 27 & $\begin{array}{l}\text { Pesticides and fungicides and urea for crops are polluting our environment and water } \\
\text { bodies? }\end{array}$ & $.7664(19160)$ \\
\hline 28 & It is our duty to protect these bodies & $.9285(23212)$ \\
\hline 29 & $\begin{array}{l}\text { If government passes a regulation to protect water bodies and pushes for clean water, } \\
\text { I am willing to pay more tax to implement these laws. }\end{array}$ & $.1384(3460)$ \\
\hline 30 & I will support a subject on natural water and protection in schools and classes & $.2864(7160)$ \\
\hline 31 & I will vote for a candidate for water policies and protection & $.0752(1880)$ \\
\hline
\end{tabular}


Urban Population Behaviour and Knowledge Assessment

about Water Quality, Consumption, and Conservation in Pakistan

Table 2. Analysis of association between knowledge, water related behaviors, policy support, conservation, using weighted data

\begin{tabular}{|c|c|c|c|c|c|c|c|c|c|c|}
\hline & \multicolumn{2}{|c|}{$\begin{array}{c}\text { Use of routine and daily water } \\
\text { conservation strategies }\end{array}$} & \multicolumn{2}{|c|}{$\begin{array}{l}\text { Uptake of water pollution } \\
\text { cleansing devices }\end{array}$} & \multicolumn{2}{|c|}{ Pollution reduction behaviours } & \multicolumn{2}{|c|}{ Support for alternative water resources } & \multicolumn{2}{|c|}{$\begin{array}{c}\text { Support for sustainable water } \\
\text { policies }\end{array}$} \\
\hline Change in AIC & \multicolumn{2}{|c|}{6.87} & \multicolumn{2}{|c|}{24.89} & \multicolumn{2}{|c|}{13.21} & \multicolumn{2}{|c|}{14.16} & \multicolumn{2}{|c|}{9.18} \\
\hline $\mathrm{R}^{2}$ & \multicolumn{2}{|c|}{0.42} & \multicolumn{2}{|c|}{0.29} & \multicolumn{2}{|c|}{0.16} & \multicolumn{2}{|c|}{0.24} & \multicolumn{2}{|c|}{0.17} \\
\hline & $\mathrm{F}$ & Coefficient \pm SE & $\mathrm{F}$ & Coefficient \pm SE & $\mathrm{F}$ & Coefficient \pm SE & $\mathrm{F}$ & Coefficient \pm SE & $\mathrm{F}$ & Coefficient \pm SE \\
\hline Water Related Knowledge & $68.92 * * *$ & $0.18 \pm 0.03$ & $17.52 * * *$ & & $18.09 * * *$ & $0.09 \pm 0.04$ & $340.28 * * *$ & $0.32 \pm 0.01$ & $293.81 * * *$ & $0.28 \pm 0.03$ \\
\hline Age & $88.24 * * *$ & $0.16 \pm 0.02$ & & & $8.72^{* *}$ & $0.06 \pm 0.01$ & $8.14 * *$ & $0.05 \pm 0.01$ & $116.39 * * *$ & $-0.19 \pm 0.01$ \\
\hline Sex (male) & $10.94 * *$ & $-0.09 \pm 0.04$ & & & & & $26.84 * * *$ & $0.14 \pm 0.03$ & $14.28^{* * *}$ & \pm \\
\hline Education basic & $8.46^{* *}$ & $-0.07 \pm 0.01$ & $28.12 * * *$ & $-0.24 \pm 0.03$ & $5.78 * *$ & $0.03 \pm 0.05$ & $12.85 * *$ & $0.05 \pm 0.05$ & $5.23 * *$ & $-0.06 \pm 0.02$ \\
\hline Primary & $6.75^{* *}$ & $-0.06 \pm 0.02$ & $15.23 * * *$ & $-0.20 \pm 0.01$ & $4.85^{* *}$ & $-0.07 \pm 0.03$ & $8.17 * * *$ & $0.04 \pm 0.04$ & $5.39 * *$ & $-0.04 \pm 0.01$ \\
\hline High school & $12.67 * *$ & $-0.04 \pm 0.01$ & $29.75 * * *$ & $-0.18 \pm 0.04$ & $5.23^{* *}$ & $-0.06 \pm 0.02$ & $9.12 * * *$ & $0.4 \pm 0.05$ & $6.84 * *$ & $-0.05 \pm 0.01$ \\
\hline Technical diploma & $9.63 * *$ & $-0.05 \pm 0.01$ & $21.36^{* * *}$ & $-0.19 \pm 0.06$ & $5.39 * *$ & $0.03 \pm 0.01$ & $5.89 * * *$ & $0.4 \pm 0.07$ & $3.81 * *$ & $-0.02 \pm 0.03$ \\
\hline Undergraduate & $7.24 * *$ & $-0.02 \pm 0.03$ & $19.75 * * *$ & $-0.18 \pm 0.02$ & $6.84 * *$ & $0.04 \pm 0.03$ & $6.25 * * *$ & $0.3 \pm 0.03$ & $5.38 * *$ & $-0.01 \pm 0.04$ \\
\hline Graduate & $6.82 * *$ & $-0.01 \pm 0.04$ & $12.69 * * *$ & $-0.20 \pm 0.01$ & $3.81^{* *}$ & $0.05 \pm 0.05$ & $8.29 * * *$ & $0.3 \pm 0.04$ & $4.92 * *$ & $-0.01 \pm 0.01$ \\
\hline Professional degree & $3.66^{* *}$ & $-0.01 \pm 0.01$ & $14.57 * * *$ & $-0.23 \pm 0.02$ & $6.35^{* *}$ & $0.04 \pm 0.04$ & $4.25^{* * *}$ & \pm 0.16 & $6.38 * *$ & $0.05 \pm 0.05$ \\
\hline Residence urban & $2.52 * *$ & $0.5 \pm 0.01$ & $8.97 * *$ & $0.12 \pm 0.01$ & $8.56^{* *}$ & $0.02 \pm 0.04$ & $9.75^{* *}$ & $0.6 \pm 0.06$ & $5.46^{* *}$ & $0.04 \pm 0.04$ \\
\hline Lahore city & $6.34 * *$ & $0.6 \pm 0.01$ & $7.32 * *$ & $0.11 \pm 0.01$ & $7.36^{* *}$ & $0.01 \pm 0.06$ & $32.84 * * *$ & $0.28 \pm 0.04$ & 3.78 & $0.03 \pm 0.03$ \\
\hline $\begin{array}{l}\text { Gujranwala } \\
\text { city }\end{array}$ & $4.18 * *$ & $0.4 \pm 0.05$ & $8.56^{* *}$ & $0.14 \pm 0 . .02$ & $5.38 * *$ & $0.06 \pm 0.04$ & $31.24 * * *$ & $0.6 \pm 0.06$ & $8.64 * *$ & $0.18 \pm 0.04$ \\
\hline $\begin{array}{l}\text { Rawalpindi } \\
\text { city }\end{array}$ & $5.89 * *$ & $0.4 \pm 0.07$ & $6.78 * *$ & $0.13 \pm 0.04$ & $4.92 * *$ & $0.04 \pm 0.05$ & $25.12 * * *$ & $0.7 \pm 0.04$ & $5.67 *$ & $0.13 \pm 0.06$ \\
\hline Multan city & $7.43 * *$ & $0.3 \pm 0.03$ & $7.85 * *$ & $0.12 \pm 0.03$ & $5.85^{* *}$ & $0.08 \pm 0.05$ & $23.78 * * *$ & $0.9 \pm 0.05$ & $6.84 * *$ & $0.16 \pm 0.08$ \\
\hline Sialkot city & $5.77 * *$ & $0.3 \pm 0.04$ & $6.82 * *$ & $0.15 \pm 0.01$ & $6.98^{* *}$ & $0.05 \pm 0.03$ & $24.89 * * *$ & $0.05 \pm 0.05$ & $3.81 * *$ & $0.05 \pm 0.05$ \\
\hline Annual rainfall & $3.22 * *$ & $0.2 \pm 0.16$ & $4.28 * *$ & $0.14 \pm 0.01$ & $5.25^{* *}$ & $0.04 \pm 0.02$ & $12.75^{* * *}$ & $0.04 \pm 0.04$ & $6.35^{* *}$ & $0.04 \pm 0.04$ \\
\hline $\begin{array}{l}\text { Experience of } \\
\text { water shortage }\end{array}$ & $2.18 * *$ & $0.6 \pm 0.06$ & $3.33 * *$ & $0.10 \pm 0.01$ & $3.22 * *$ & $0.6 \pm 0.04$ & $4.25 * *$ & $0.4 \pm 0.05$ & $8.56^{* *}$ & $0.02 \pm 0.04$ \\
\hline $\begin{array}{l}\text { Health affected due to } \\
\text { water pollution }\end{array}$ & $9.82 * *$ & $0.7 \pm 0.04$ & $4.86^{* *}$ & $0.12 \pm 0.01$ & $2.54 * *$ & $0.06 \pm 0.04$ & $3.25 * *$ & $0.4 \pm 0.07$ & $7.36^{* *}$ & $0.01 \pm 0.06$ \\
\hline Supporting water policy & $4.97 * *$ & $0.9 \pm 0.05$ & $4.35 * *$ & $0.13 \pm 0.02$ & $1.56^{* *}$ & $0.07 \pm 0.06$ & $3.45^{* *}$ & $0.3 \pm 0.03$ & $5.38^{* *}$ & $0.06 \pm 0.04$ \\
\hline Supporting water education & $7.38 * *$ & $0.8 \pm 0.04$ & $3.22 * *$ & $0.14 \pm 0.03$ & $2.65 * *$ & $0.08 \pm 0.01$ & $4.29 * *$ & $0.6 \pm 0.06$ & $4.92 * *$ & $0.10 \pm 0.01$ \\
\hline Water infinite resource & & $0.11 \pm 0.04$ & $8.62 * *$ & $0.12 \pm$ & $3.92 * *$ & $0.04 \pm 0.01$ & $5.48 * *$ & $0.7 \pm 0.04$ & $5.85^{* *}$ & $0.12 \pm 0.01$ \\
\hline Environmental education & & $0.7 \pm 0.02$ & $7.69 * *$ & $0.14 \pm$ & $2.25 * *$ & $0.02 \pm 0.04$ & $6.34 * *$ & $0.9 \pm 0.05$ & $6.98 * *$ & $0.13 \pm 0.02$ \\
\hline
\end{tabular}




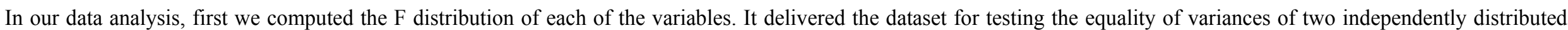

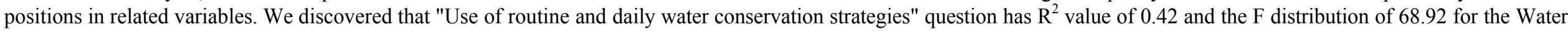

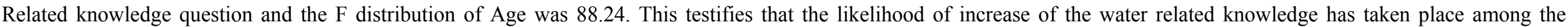

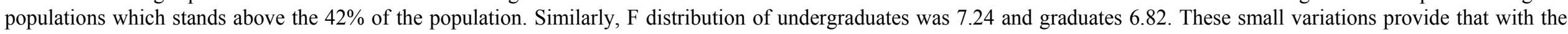
higher education in the nations added care and more attention towards healthy and safe use of water is taking place.

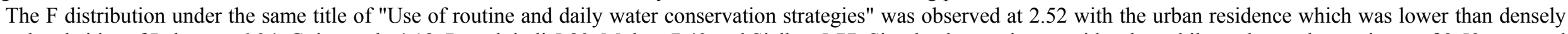

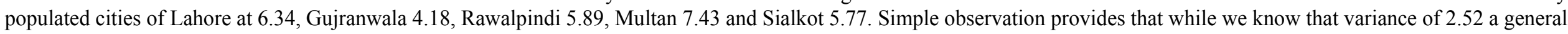

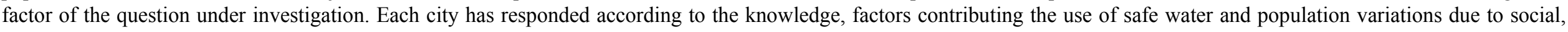
environmental and educational factors.

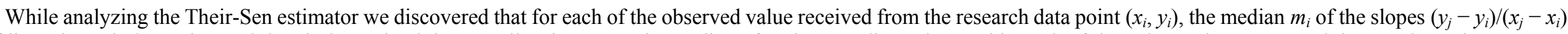

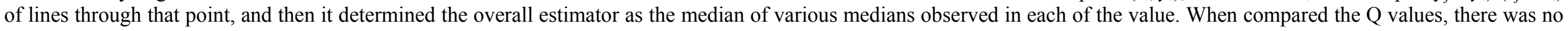

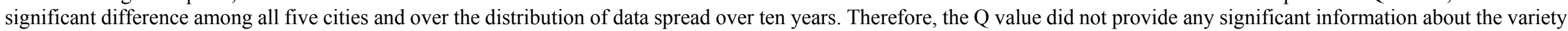

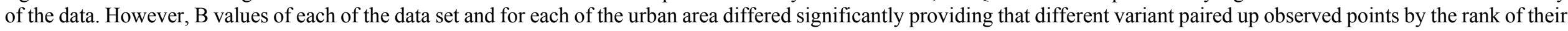

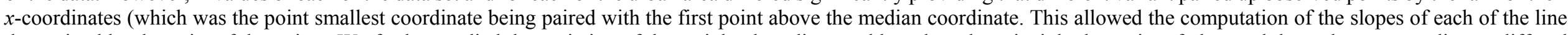

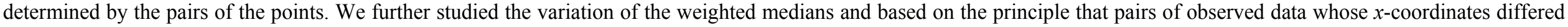
greatly and significantly had accurate slope and thus we concluded them of having higher weight.

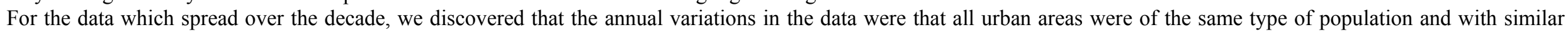
background and then finding the median of the slopes of the lines determined by this restrictive set of data points and pairs.

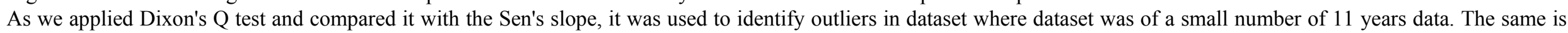

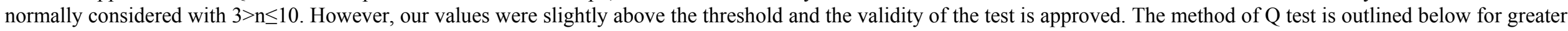

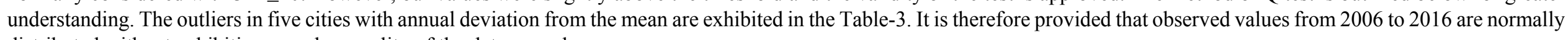
distributed without exhibiting any abnormality of the data spread

Table 3. Water Knowledge 2006-2016

\begin{tabular}{|c|c|c|c|c|c|c|c|c|c|c|c|c|c|c|c|}
\hline $\begin{array}{c}\text { Water } \\
\text { Knowledge } \\
\text { 2006-2016 }\end{array}$ & & & & & & Sen's sl & estimate & & & & & & & & \\
\hline Time series & $\begin{array}{l}\text { First } \\
\text { year }\end{array}$ & $\begin{array}{l}\text { Last } \\
\text { Year }\end{array}$ & $\mathrm{n}$ & Test Z & Significant. & Q & Qmin99 & Qmax99 & Qmin95 & Qmax95 & B & Bmin99 & Bmax99 & Bmin95 & Bmax95 \\
\hline Gujranwala & 2006 & 2016 & 11 & -3.50 & $* * *$ & -0.063 & -0.089 & -0.034 & -0.085 & -0.044 & 1.30 & 1.46 & 1.10 & 1.44 & 1.19 \\
\hline Lahore & 2006 & 2016 & 11 & -2.47 & $*$ & -0.018 & -0.040 & 0.000 & -0.035 & -0.004 & 0.59 & 0.73 & 0.44 & 0.73 & 0.47 \\
\hline Multan & 2006 & 2016 & 11 & -2.47 & * & -0.013 & -0.020 & 0.002 & -0.019 & -0.004 & 0.48 & 0.52 & 0.40 & 0.51 & 0.45 \\
\hline Rawalpindi & 2006 & 2016 & 11 & -3.78 & $* * *$ & -0.034 & -0.053 & -0.021 & -0.046 & -0.025 & 0.69 & 0.82 & 0.60 & 0.79 & 0.61 \\
\hline Faisalabad & 2006 & 2016 & 11 & -2.27 & $*$ & -0.010 & -0.029 & 0.002 & -0.023 & -0.002 & 0.25 & 0.42 & 0.16 & 0.37 & 0.18 \\
\hline
\end{tabular}




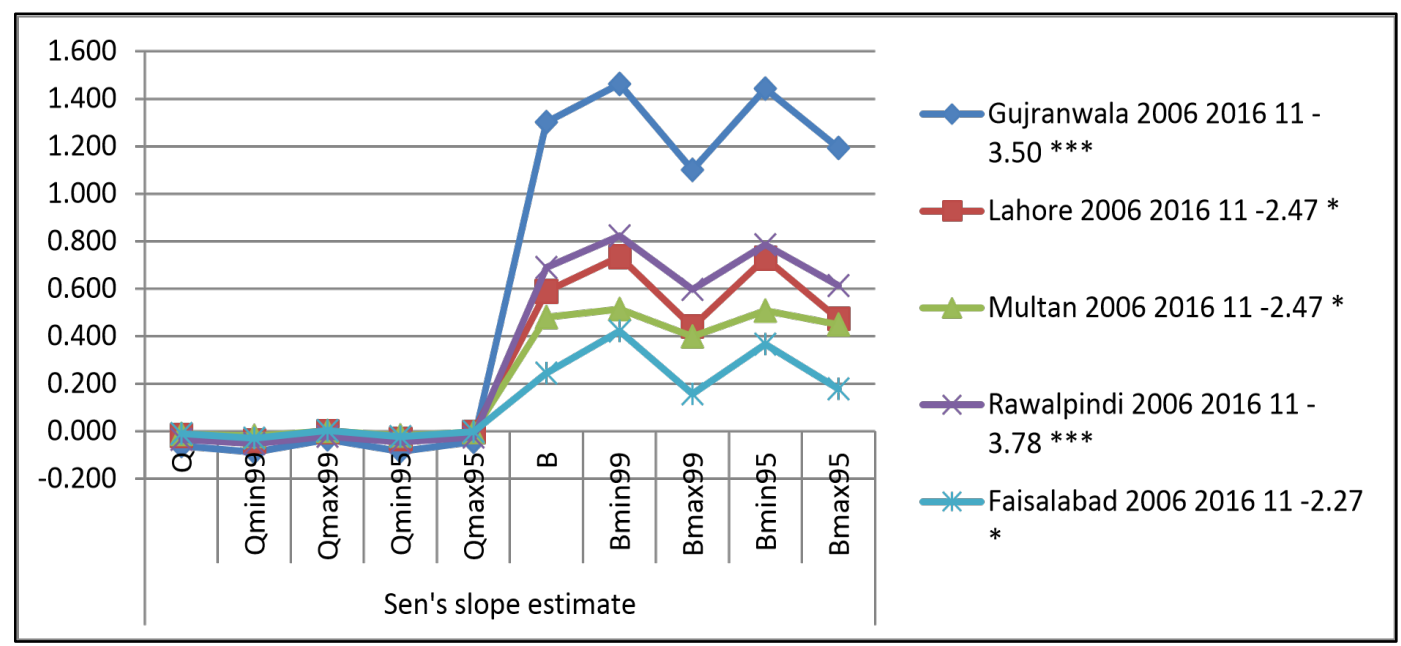

Figure 2. Graphic Output (Sen'S Slope Estimate)

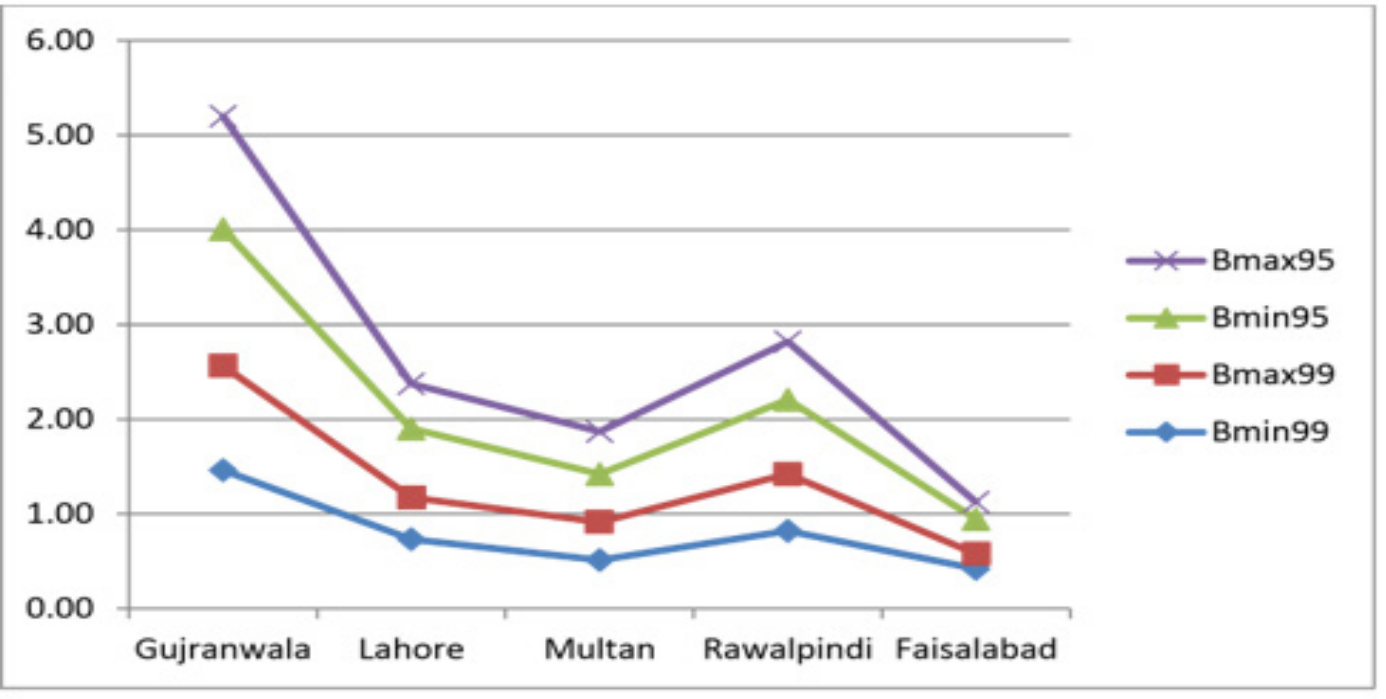

Figure 3. (Logrank Maximum Test)

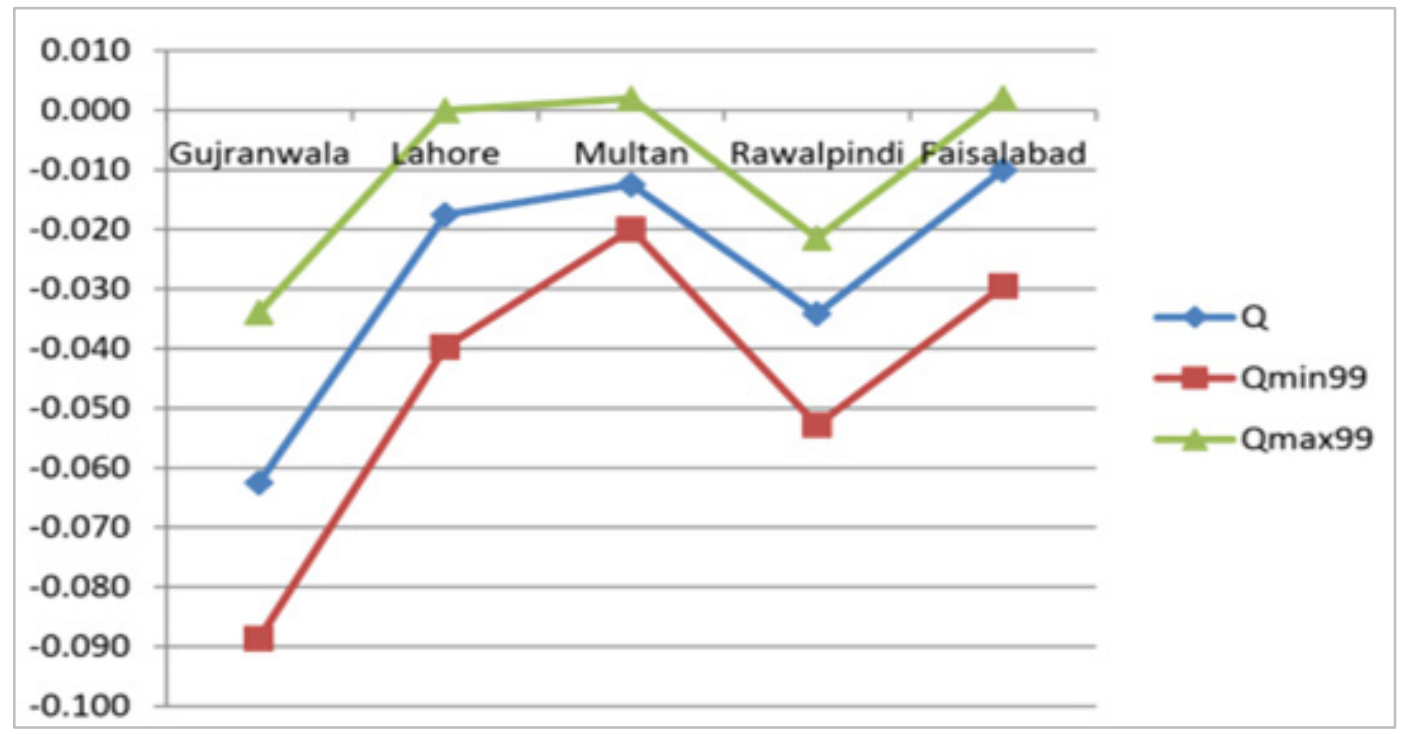

Figure 4. (Logrank Minimum Test) 


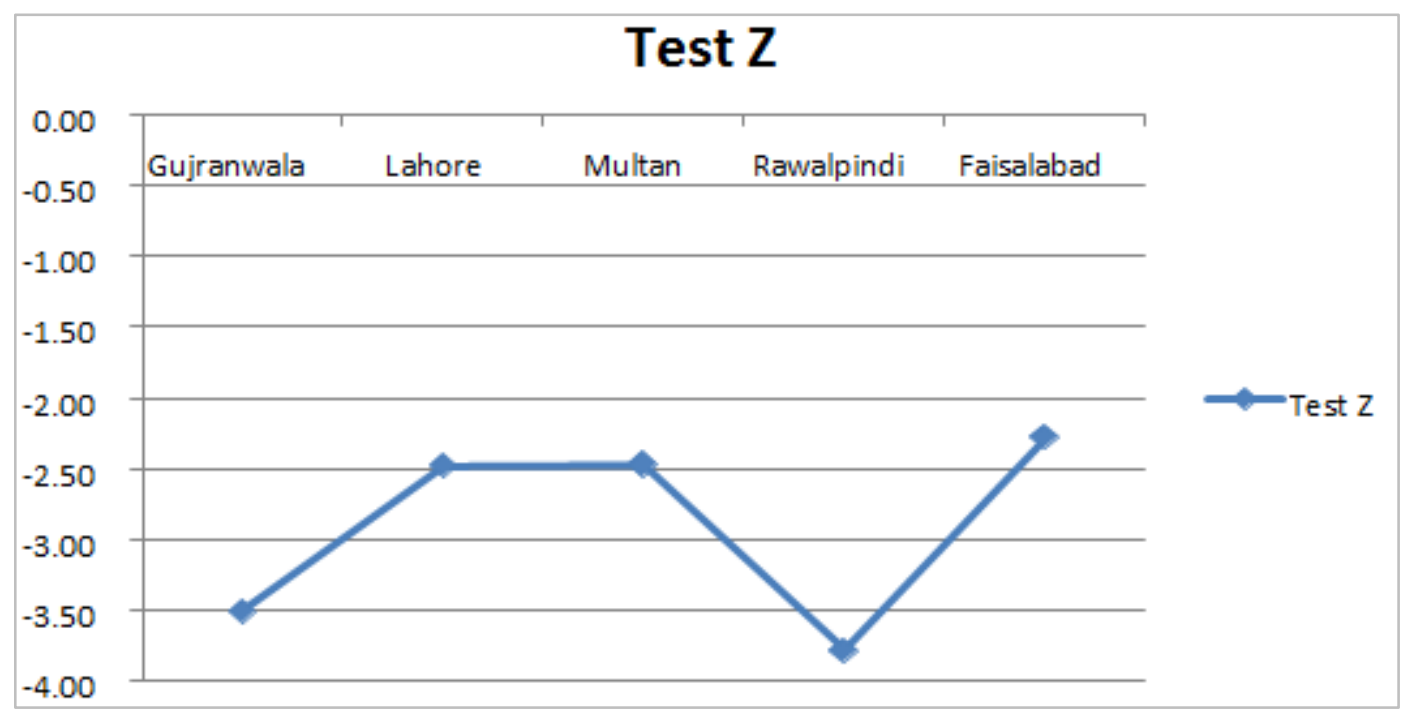

Figure-5. Test $Z$

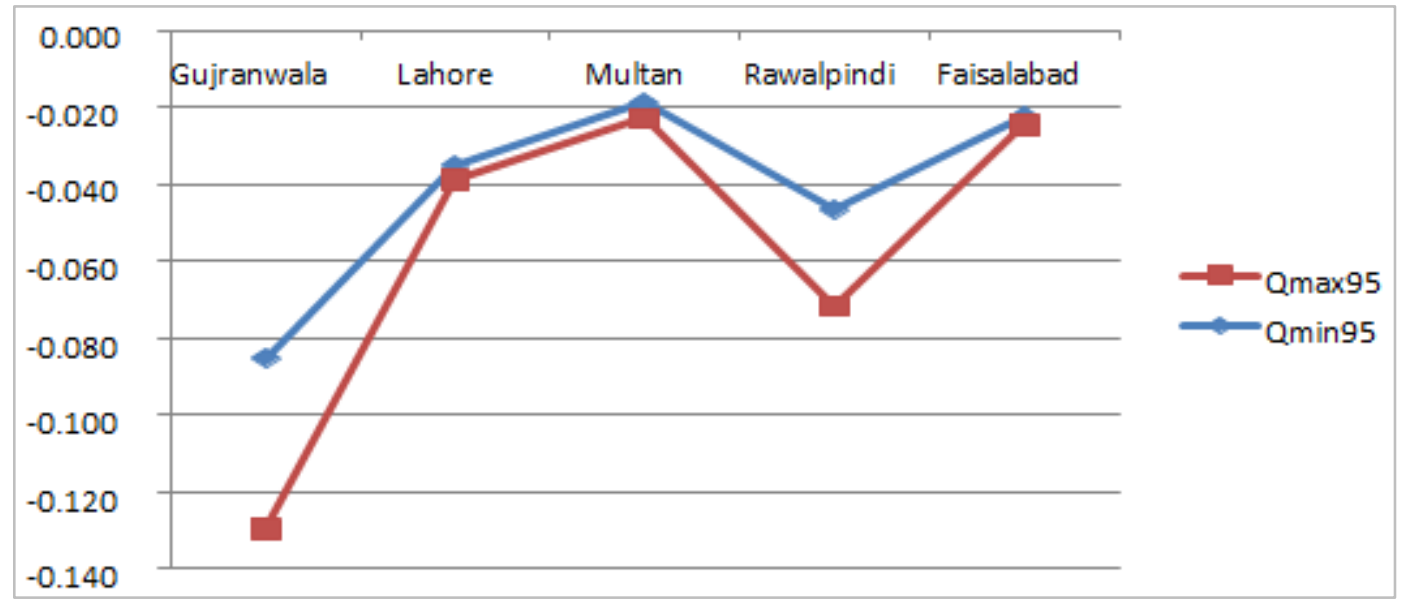

Figure-6

Additionally, we applied the $\mathrm{Z}$ test to determine whether population means are different when the variances are calculated and are exhibited in the data tables for a large sample size of 25,000 population. With the Central limit theorem, it is already known that the data is normally distributed, and the $\mathrm{Z}$ test has validated that the same is exhibited in the data plots. The data accuracy is hereby confirmed that there was no data which could be considered not fit for our research purposes.

\section{Conclusions}

The research findings proved that lack of water knowledge has caused greater negative impacts in psychological, economic and health of populations across South Asia. The research further proved that the government lack of water policies is causing alarming health related issues which are often visible in outbreaks of diseases and outbursts of large-scale emergencies.
Hospitals and health care institutions are not properly staffed or equipped to handle water borne diseases and are ill equipped in the form of policies, practices, customer service approaches, administration of medicines and lack the professional behavior of respect and honor to a clear majority of the poor population's victim of the water-borne issue. There are very few water institutions which then are staffed with non-technical and clerical staff having zero knowledge regarding the water, its chemistry, and its cycle as well as management and storage practices. The research identified that the water and its dependency of life while is crucial but is being treated as an alien within the disciplines of human health, sustainability, and the development. Water based degrees and education as well the amendment in centuries old legislation is needed and shall be mandated by the World Health Organization and other global health agencies.

Development of water boards and staffed with water scientists is also required which will have enormous health related benefits because it will cut the sickness and 
outbreak of diseases into significantly smaller fraction. Educated public regarding the preparation of drinks, sodas, and foods will develop into a healthy nation free of psychological and ill-mannered practices. Regulation and establishment of the potable and consumable fluid industries is also the basic requirement of the time because most of the water-borne sickness arises from the unhygienic environment and practices. Local health departments also need to develop programs to certify food service managers which will, in turn, assure that healthy practices are being adopted and the nation will slowly overcome the water-borne diseases and will adopt to healthy and safe practices of food and drink preparations.

\section{REFERENCES}

[1] ADB (Asian Development Bank). Energy Trade in South Asia: Opportunities and Challenges. Asian Development Bank, Manila. Retrieved from https://www.adb.org/publications/energy-trade-south-asiaopportunities-and-challenges, 2011.

[2] Scott, S. Pierce, M. Pasqualetti, A. Jones, B. Montz, J. Hoover. Policy and institutional dimensions of the water-energy nexus, Energy Policy, 39 (10), pp. 6622-6630, 2011.

[3] Biggs, J., Duncan, P. Atkinson, J. Dash. Plenty of water, not enough strategy: how inadequate accessibility, poor governance and a volatile government can tip the balance against ensuring water security: the case of Nepal, Environ. Sci. Policy, 33, pp. 388-394, 2013.

[4] K. Hassan, P. Pelkonen, P. Halder, A. Pappinen. An analysis of cross-sectional variation in energy consumption pattern at the household level in disregarded rural Bangladesh, J. Basic Appl. Sci. Res., 2 (4), pp. 3949-3963, 2012.

[5] Sjarkowi, H. F. Is poverty eradication possible in the peatland areas of Kalimantan Tengah, Social and Material Life of Bottled Water (pp. 99-114). MIT Press. Retrieved from http://www.jstor.org/stable/j.ctt16wd0bv.9 Territories, Canada. Arctic, 60(1), 37-46. Retrieved from http://www.jstor.org/stable/40513156. Twentieth Century Literature, 43(2), 144-161. doi:10.2307/441566, 2007.
[6] Crow, B., N. Singh. The management of international rivers as demands grow and supplies tighten: India, China, Nepal, Pakistan, Bangladesh https://www.tandfonline.com/doi/abs/10.1080/1473648090 3116826, 2009.

[7] Sellers, C. The Artificial Nature of Fluoridated Water: Between Nations, Knowledge, and Material Flows. Osiris, 19, 2nd series, 182-200. Retrieved from http://www.jstor.org/stable/3655239, 2004.

[8] Cullen, P. Knowledge Investments Underpinning National Water Reform. In Cullen V. (Ed.), This Land Our Water: Water Challenges for the 21st Century (pp. 95-103). ATF (Australia). http://www.jstor.org/stable/j.ctt163t8n7.12, 2011.

[9] Nouraie-Simone, F. Journal of American Ethnic History, Vol. 31, No. 4, Summer 2012 31(4), 80-81, 2012.

[10] Molden, D. Water for food, water for life a comprehensive assessment of water management in agriculture. EarthScan London and International Water Management Institute, 2007 Colombo ISBN-13: 978-1844073962. Retrieved from https://link.springer.com/article/10.1007\%2Fs10795-008-9 044-8, 2007.

[11] Chang, S. J. Business groups in East Asia: Post-crisis restructuring and new growth. Asia Pacific Journal of Management, 23: 407-417, 2006.

[12] Lu, Y., Tsang, E.W.K. \& Peng, M.W. Asia Pac J Manage. 25: 361. Meets Traditional Knowledge: Water and Climate in the Sahtu (Great Bear Lake) Region, Northwest, 2008.

[13] HEC, Pakistan. 2017. Universities approved list, http://www.hec.gov.pk/english/universities/pages/recognis ed.aspx cited on May 14, 2017. India, China, Nepal, Pakistan, Bangladesh, India Rev., 8 (3), pp. 306-339 Indonesia.

[14] Welbourne, M. 2001. Public knowledge. In Knowledge (pp. 69-76). McGill-Queen's University Press. Retrieved from http://www.jstor.org/stable/j.ctt8099f.7

[15] Hawkins, G., Potter, E., \& Race, K. 2015. Enacting Water Scarcity in Chennai. In Plastic Water. Retrieved from: https://www.researchgate.net/publication/305002327_Enac ting_Water_Scarcity_in_Chennai, 2015.

[16] Vining A., Weimer D., Weimer D., and Vining A. (Eds.). Investing in the Disadvantaged: Assessing the Benefits and Costs of Social Policies (pp. 1-16). Georgetown University Press. http://www.jstor.org/stable/j.ctt2tt7mg.6, 2009. 